\section{Original Research}

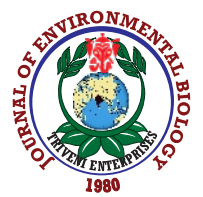

DOI : http://doi.org/10.22438/jeb/41/2(SI)/JEB-09

Journal Home page : www.jeb.co.in $\star$ E-mail : editor@jeb.co.in Journal of Environmental Biology

\title{
Hydrodynamic zones of fissure-karst waters of Zemo Imereti Plateau in the Republic of Georgia
}

\author{
Z. Lezhava', L. Asanidze ${ }^{1 *}$, K. Tsikarishvili', N. Chikhradze ${ }^{2}$, L. Gadrani ${ }^{1}$ and G. Chartolani ${ }^{1}$ \\ ${ }^{1}$ Vakhushti Bagrationi Institute of Geography, Iv. Javakhishvili Tbilisi State University. Tbilisi, 0177, Georgia \\ ${ }^{2}$ School of Natural Sciences and Engineering, llia State University. Tbilisi, 0162, Georgia \\ *Corresponding Author Email : lasha.asanidze@tsu.ge
}

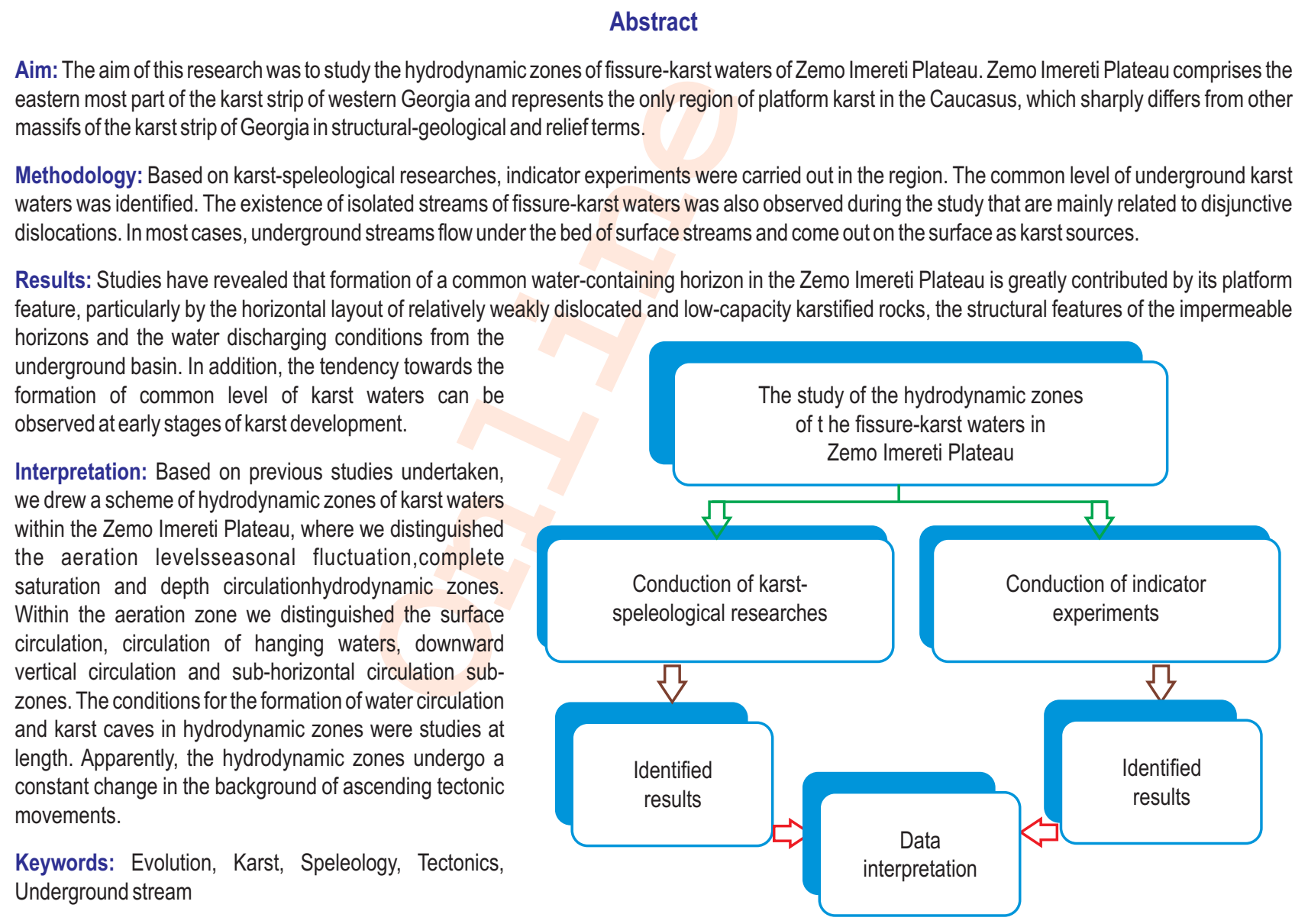

How to cite : Lezhava, Z., L. Asanidze, K. Tsikarishvili, N. Chikhradze, L. Gadrani and G. Chartolani: Hydrodynamic zones of fissure-karst waters of Zemo Imereti Plateau in the Republic of Georgia. J. Environ. Biol., 41, 337-343 (2020). 


\section{Introduction}

Several studies (Tintilozov, 1976, Maruashvili, 1973, Lezhava, 2015, Lezhava et al., 2015) and previous experience indicate that the scale of cave origination is determined not only by the capacity of karstified rocks and by openness or density of fissures developed in them, but by the peculiarities of accumulation and discharging underground waters in the karst massifs. It is now confirmed that even in the massifs with the structure of karstified rocks that are fragmented by dense network of fissures, karst caves (empty areas) cannot be formed without long-term corrosion-erosion impacts of significant water streams.

The karst region of Zemo Imereti Plateau consists of easternmost part of the karst strip of western Georgia and is the only platform karst region in the Caucasus (Lezhava, 2015; Lezhava et al., 2015, 2019a; 2019b; Asanidze et al., 2017). The Zemo Imereti Plateau sharply differs from other massifs of karst strip of Georgia and occupies the central, relatively elevated part of intermountain plain of Georgia. Most part of the surface of plateau is located at a height of $400-800 \mathrm{~m}$ above sea level. It is characterized by deep river gorges and the peculiar soft relief of watershed areas. The uniform surface of plateau in itself is dissected in relatively small plateaus with plain surfaces and steep slopes by deep (100-250 m) canyon gorges of the Kvirila River and its tributaries (Jruchula, Nekrisa, Bogiristskali, Rganisghele, Katskhura, Buja, Sadzalikhevi, etc.). Important information on the geology of study area can be found in several publications (Gamkrelidze, 1933; Kuznetsov, 1927; Janelidze, 1940a, 1940b; Kakhadze, 1941, 1948; Geguchadze, 1973; Gudjabidze, 2003; Chikhelidze, 1948; Shiriashvili and Vashakidze, 1972). The boundary of the karst region of Zemo Imereti Plateau coincides with the surface contact line of the Cretaceous limestones with older formations (Bajocian porphyritic suite - in the north and east, and the Middle Paleozoic granitoids- in the south and west), which is the geological substrate of the karst (Fig. 1). Existence of a solid Hercynian platform has stipulated the layout feature of Mesozoic-Cenozoic suites on it (sub-horizontal or slightly sloped), which is represented mainly by the Valanginian-Hauterivian, Barremian and the Turonian-Danianlimestones, and the Tertiary clays and sandstones. The platform structure of the plateau has played an important role in the origine and development of surface and underground karst forms and underground karst flows.

\section{Materials and Methods}

In the course of this research, field geomorphological and karst-speleological large scale surveys were carried out. To prove the origin trend of common level (common system) of karst waters at early stages of karst development, a correlation of hypsometric levels of the entries of horizontal caves and outlets of sources was made. On the basis of field surveys, boreholes and geological section analyses, the topography of upper tectonic was restored
(Mesozoic-Cenozoic) from the layer of Zemo Imereti structural plateau, which had a significant impact on the formation of underground karst waters and their movement peculiarities.

On the basis of using dye water tracing (indicator experiment) method, the movement routes of underground karst waters and their discharging areas were identified. The common levels of karst waters and the isolated streams of fissure-karst waters were detected.

\section{Results and Discussion}

On the basis of speleological survey and indicator experiments carried out, the common level of underground karst waters was identified. It is noteworthy that together with the common level of underground waters, the existence of isolated streams of fissure-karst waters was also observed i.e., mainly related to disjunctive dislocations. In most cases, the underground streams flew under the beds of surface streams and appeared on the land surfaceas karst springs (Fig.2).

The accumulation of water and formation of a common water-containing horizon within the Zemo Imereti Plateau is significantly contributed by its platform character, i.e., slightly angled or horizontal layout of karstified rocks with weak dislocation and low thickness, as well as the structural features of the water impermeable horizon and the conditions for water discharge from the underground basin. It is noteworthy that the Kvirila River and its tributaries do not cross the limestone cover to its bottom - to Likhipeneplain beyond the city of Chiatura. Therefore, all morphologically distinguished plateaus on both sides of the Kvirila River have a common limestone foundation, which, together with structural peculiarities and all abovementioned conditions, creates favorable condition for the formation of common level of karst waters.

The trend of origination of common level of karst waters (or the common system) is observed at early stages of karst development, the proof of which is the location of entrances of horizontal caves and the outlets of sources at almost similar hypsometric levels (Fig. 3).

Karst caves in the Zemo Imereti Plateau are mostly the product of evolution of hydrodynamic zones. This evolution had started from Upper Pleistocene and is still active today. During this long process that has been in progress on the background of tectonic (neotectonic) movements, the hydrodynamic zones have undergone constant modification: dying-drying of upper zones and conceiving-watering of the underlying zones. Exactly, the ascending tectonic movements and alternation of delayed epochs has stipulated the storey-like layout of caves in the plateau.

Based on the schemes of hydrodynamic zones presented by several workers (Sokolov, 1962, Maksimovich, 1963, 

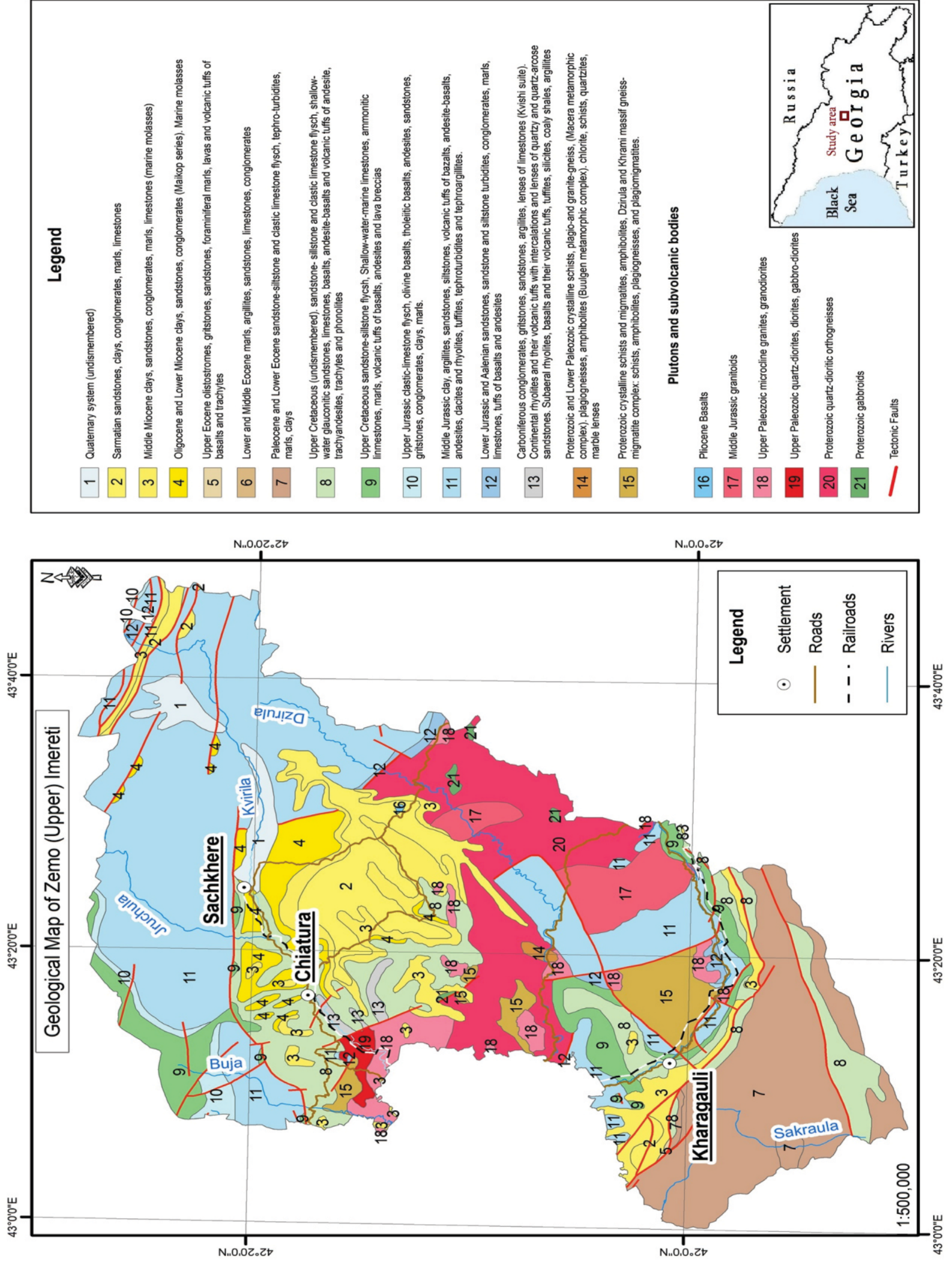

Fig. 1 : Geological map of Zemo Imereti Plateau (Gudjabidze, 2003). 
Tintilozov, 1976, Dublansky, 1977, Kiknadze, 1979) together with the materials obtained by us during field and experimental surveys for last several years, we have distinguished 4 zones within the Zemo Imereti Plateau: aeration or vertical circulation zone, zone of seasonal fluctuation of levels, complete saturation zone and depth circulation hydrodynamic zone. Within the aeration zone, sub-zones were also distinguished (Fig. 4).

In the aeration zone $(I)$, there is a downward movement of karst waters, fed by infiltration and influation of meteorological and surface waters. The absorption of surface waters is mainly related to tectonically weakened areas, as well as karst forms (sinkholes, ponors and caves). The karst processes in this zone are entirely dependent on the above-mentioned precipitation, therefore, their intensive course coincides with the periods of abundant atmospheric precipitation and snow melting. The intensity of karst processes in the aeration zone is characterized by seasonal rhythmicity, which is also reflected on the sources related to this zone. The lower boundary of the above mentioned zone conditionally coincides with the surface, which underground waters reach during the period of maximum high water levels. Wells, shafts and abysses are formed in the aeration zone. The width aeration zone is mainly 150-200 $\mathrm{m}$ within the study area.

Surface circulation sub-zone (la) allocated by us in the aeration zone is directly supplied with atmospheric waters. The evaporation of part of atmospheric precipitations occurs in this sub-zone, and it produces surface flows, especially on the

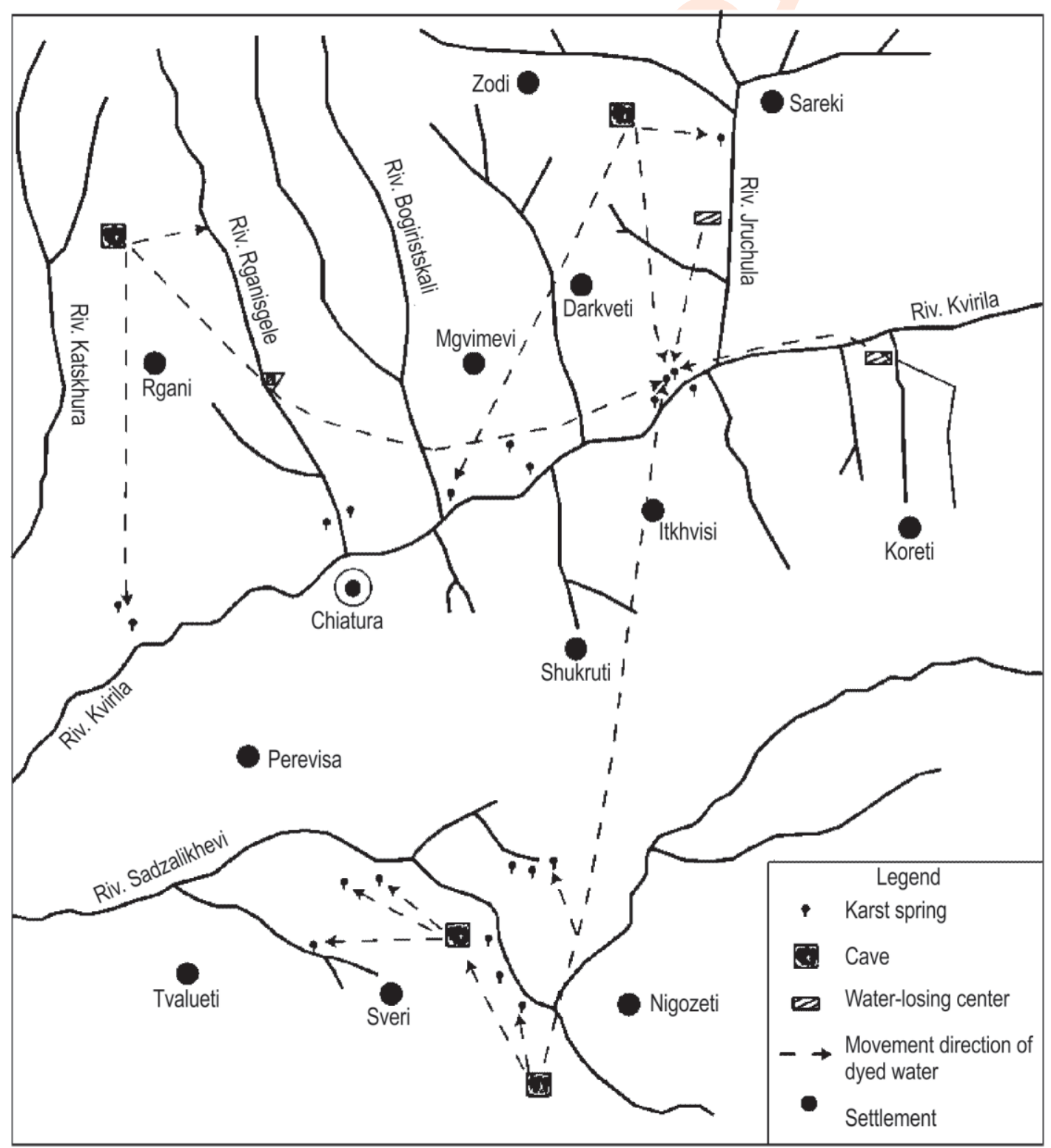

Fig. 2 : Movement scheme of underground waters obtained as a result of indicator tests in the Zemo Imereti Plateau. 
a

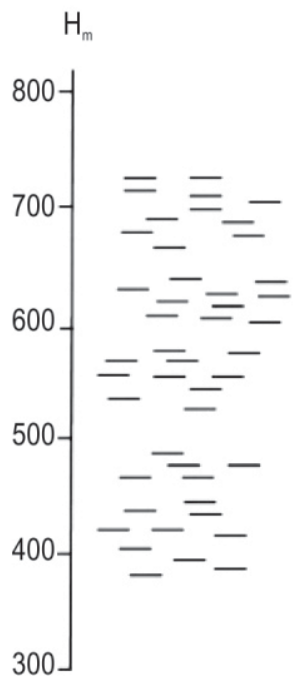

$$
H_{m}
$$

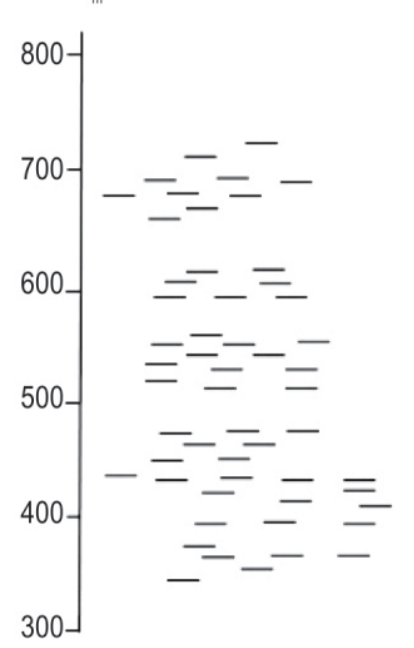

Fig. 3 : Scale of distribution of hypsometric levels of horizontal caves entrances: (a) karst sources outlets and (b) in the Zemo Imereti Plateau.

substrate built by Tertiary sediments. In the areas, where the latter is washed away and the Upper Cretaceous limestone layers are outcropped on the surface, the waters produced from the atmospheric precipitations, except the loss due to evaporation, completely leak into the fissures developed in the limestone layers of the same age and disappear into the depth through underground channels.

On limestone surface in the surface circulation sub-zone, these waters generate surface karst forms - corries, sinkholes and transitional to depth forms - karst wells that are so widely presented here. In the aerial zone, the circulation sub-zone of hanging waters $(\mathrm{Ib})$ is significantly distinguished conditioning the outlets of small-scale sources in the plateaus and canyon slopes of the study area. In addition, there are also permanent and periodically active hanging waters. Latter are especially represented during heavy rains or spring snow melting period. The hanging sources are mainly related to the outcrops of relatively hardly soluble rocks.

In aeration zone, the downward vertical circulation subzone of underground waters is distinguished with its wide distribution. We consider that the opinion of Tintilozov (1976) and Kinknadze (1979) on the existence of sub-horizontal movement sections(especially in the conditions of platform karst) of underground streams within the aeration zone (especially in its lower level) is quite right. Within the study area, at lower level of the aeration zone, there is also an evidence of sub-horizontal circulation sub-zone (Id) of underground waters, which occasionally stipulates a significant decrease in their speed. For example, the caves - Namdzvleviklde, Shvilobisa and others are entirely generated in the aeration zone and represented by the sections of vertical and sub-horizontal circulation. Most of the relic caves are located within the aeration zone of the region. Rganisklde, Tsilto III, Gvarjilasklde, Nakhiznebi, Sachinkia, Nigozeti, Bnelaklde, etc. where following the waters are no longer.

There is a zone of seasonal fluctuation (II) located on the border of aeration zone and complete saturation zone within the Zemo Imereti Plateau, which is distinguished by seasonal variability of karst water levels. Sokolov (1962) points out that this zone is of transitional nature regarding neighboring hydrodynamic zones and with the dependence on the underground water levels (the latter depends on climate conditions), sometimes it joins with aeration zone, and sometimes - with complete saturation zone. Therefore, as mentioned above hydrodynamic zones of underground waters are in close relation with each other. For example, the aeration zone waters can get in the complete saturation zone from the seasonal fluctuation basin and take part in feeding of deep circulation zone sources itself.

In the study area, high activity of karst as well as, in general, the full spectrum of karstification and some of the karst sources; active periodically or permanently; are related to seasonal fluctuation zone. The increase or decrease of debit of these sources last for several weeks, according to duration of humid or dry periods. The capacity of level's seasonal fluctuation within the structural plateau would be measured by 2-3 tens of meters, the evidence of which is a significant seasonal fluctuation of levels on almost all major karst sources (Ghrudo, Monastery, Lezhubani, Tiri, etc.). In addition, during high water period, as per field surveys, head of some sources temporarily shifted up by several tens of meters. This fact indicates that there are cavities of significant capacity in the border of aeration and complete saturation zones, where water levels significantly vary in relation to the abundance of atmospheric precipitations. The main reason for the rise of underground river levels in karst cavities is not only the poor pass-through ability of fissure, but also the colmatage of cannals.

In the study area, complete saturation zone (III) extends at the level of Kvirila River bed, or below it. In this zone, the karst waters moved in the horizontal direction. Its lower boundary was mainly determined by the location of local erosion basis or the existence of water impermeable sublayers. Horizontal caves developed in this zone. Permanently active and abundant-debit sources (Ghrudo, Monastery, beyond Kvirila water gryphon etc.) are also associated with it, on the expense of which the city of Chiatura and its surrounding are supplied with water. Waters that are formed in the complete saturation zone are discharged in the form of vaucluse sources at the main river level, or flow below this level and flow out in the ground surface in the form of sources as proved by the results of indicator tests (Lezhava et al., 1989, 1991). 


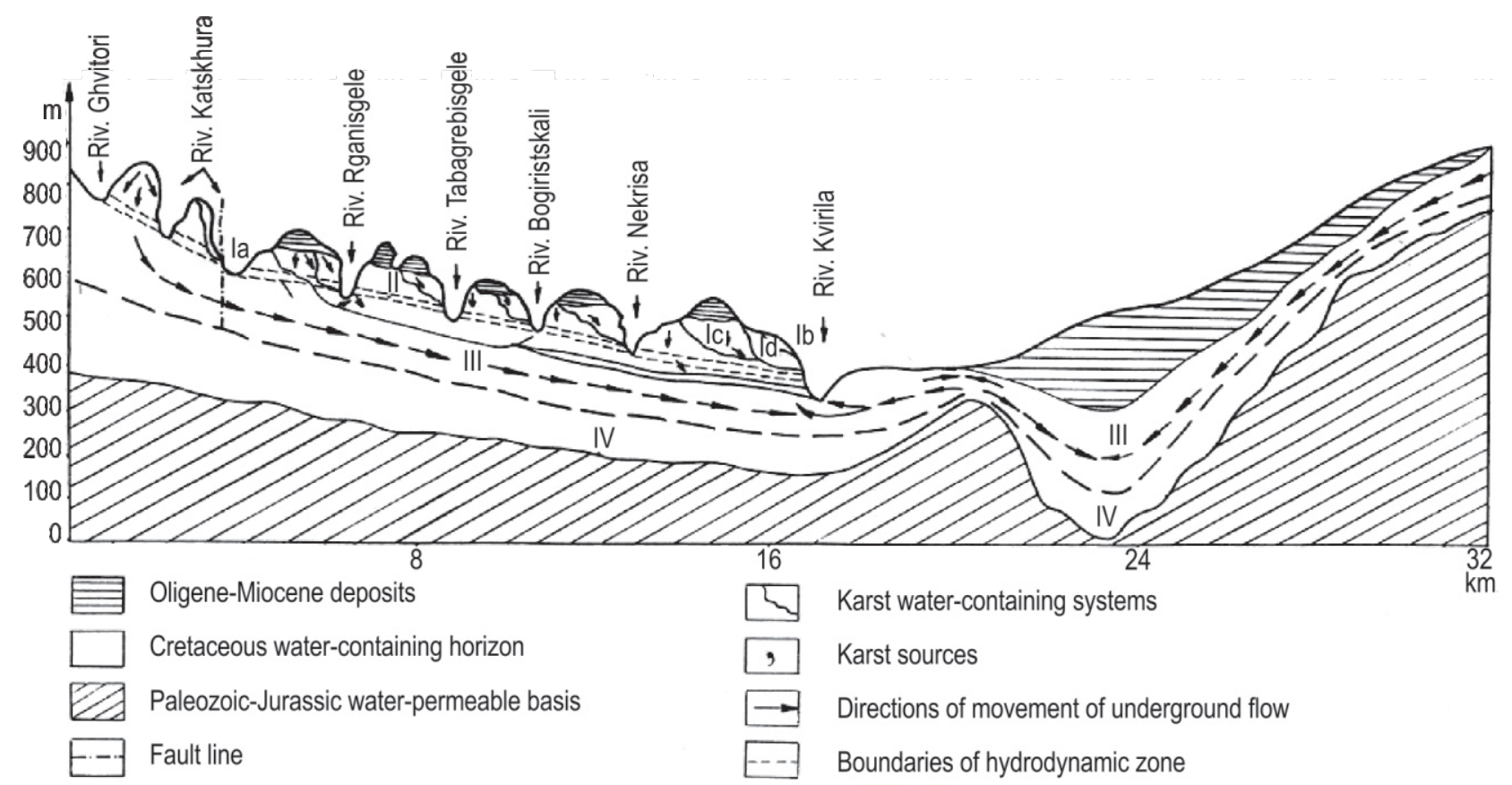

Fig. 4: Scheme of karst-hydrogeological basins and hydrodynamic zones of karst waters in the Zemo Imereti Plateau; Hydrodynamic zones: I-Aeration zone; II - Levels' seasonal fluctuation zone; III-Complete saturation zone; IV-Depth circulation zone; Sub-zones: la - Surface circulation sub-zone; IbHanging waters sub-zone; Ic-Downward vertical circulation sub-zone; Id-Sub-horizontal circulation sub-zone.

The above-mentioned pressured water outlets (water gryphons) are mainly related to the locked karst systems and distribution areas of Barremianlime stones. Latter are good collectors of underground water. The pressured water outlets in the Katskura, Rganisghele and Jruchula river gorges were reported by us, where there is an anticipation of existence of extensive basins of underground waters with complicated waterexchange (Lezhava, 2015).

The mentioned basins are supposed to represent prospective areas of obtaining drinking waters. The formation of flows in the complete saturation zone is supported by significant altitudinal difference (about 600-700 m) among the absorption and discharging areas of atmospheric waters, resulting in hydrostatic pressure in the fissures; in addition, common sinking of karstified rocks from the peripheries of structural plateau to the center, which mainly defines the directions of underground karst water movement within the structural plateau. The extent of limestones at a significant depth $(160-200 \mathrm{~m})$ below the local erosion basis (KvirilaRiver) within the Zemo Imereti Plateau and the common limestone basis indicate the existence of a depth circulation (IV)zone.

This is also confirmed by the results of drilling works. For example, according to Kuchhukhidze (1986) and others, in the borehole of Sachkhere (the absolute height of the borehole 450 $\mathrm{m}$ ) at a depth of 362-382 $\mathrm{m}$ from the surface (absolute height 70 $\mathrm{m})$, in the Upper Cretaceous limestones, $20 \mathrm{~m}$ thick water- containing horizons have been identified, where the water flow debit was $3.1 \mathrm{I} \mathrm{sec}^{-1}$. In the Merjevi borehole, at 385-415 m from the surface (at an absolute height of $113 \mathrm{~m}$ ) was identified with a $30 \mathrm{~m}$ thick water-containing horizon, a debit of $65 \mathrm{I} \mathrm{sec}^{-1}$.

The unpublished data of Mamulia and Gambashidze are also interesting. These authors have detected water-containing horizons at significant depths during drilling carried out in the Jruchula and Kvirilariver beds. Pumping of water from these horizons did not affect the Ghrudo and other important vaucluse sources, and the debit remained unchanged. Thus, the regime observation has established the existence of not only the depth circulation, but also the fact that the vaucluse sources connected to the Ghrudo complete saturation zone have no direct hydraulic connection with the depth circulation zone.

On the basis of field, experimental and laboratory surveys within the Zemo Imereti Plateau, the unified karsthydrogeological system (unified level) with sufficient resources of dynamic water were identified. In addition to the above mentioned system, isolated fissure-karst water systems were observed with different hypsometric location and orientation. Accumulation of water and formation of a common water-containing horizon in the Zemo Imereti Plateau is greatly facilitated by its platform character as well as structural peculiarities of water impermeable horizon and the conditions of discharging waters from the underground basin. Disjunctive dislocation seem to have a significant effect on forming isolated flows. Features of substrate 
shaping formations of study area, as well as geomorphological conditions and tectonic peculiarities, lead the character of existence and distribution of hydrodynamic zones of karst waters.

The evolution of karst cavities of Zemo Imereti Plateau is closely related to the fissure-karst waters of hydrodynamic zones (aeration, seasonal fluctuation of levels, complete saturation, depth circulation).

\section{Acknowledgment}

This work was supported by Shota Rustaveli National Science Foundation of Georgia (SRNSFG), grant number: №YS-18-096).

\section{References}

Asanidze, L., N. Chikhradze, Z. Lezhava, K. Tsikarishvili, J. Polk and G. Chartolani: Sedimentological study of caves in the Zemo Imereti Plateau, Georgia, Caucasus Region. J. Open J. Geol., 7, 465-477 (2017).

Chikhelidze, S.: Geological observations in the south-eastern part of the Dzirula massif. Works of the Inst. Geol. Acad. of Sc. of Georgia. Vol. IV (IX), Tbilisi (in Georgian) (1948).

Dublyansky, V.N.: Karst caves and mines of the Mountain Crimea. Leningrad (in Russian) (1977).

Gamkrelidze, P.D.: The geological structure of the part of the Dzirula and Chkherimela river gorges. - Bulletin of the Institute of Geology of Georgia. Vol. I, No 2, Tbilisi. (in Russian) (1933).

Geguchadze, Sh.: Geology and development history of the Rioni-Kvirila watershed. Tbilisi (in Georgian) (1973).

Gudjabidze, G.E.: Geological map of Georgia, Scale 1:500 000. (Editor: Gamkrelidze et al.).GeorgianState Department of Geology and National Oil Company Saqnavtobi. Tbilisi, Georgia. (in Georgian) (2003).

Janelidze, A.: Geological observations in Okriba and in the adjacent parts of Racha and Lechkhumi. Tbilisi (in Russian) (1940a).

Janelidze, A.: The problem of Georgian block.Bulletin of the ASGSSR,vol. 3, No. 1 and 2, Tbilisi (in Georgian) (1940b).

Kakhadze, I.R.: To the stratigraphy of the Upper Cretaceous of the northern periphery of the Dzirula massif. Bulletin of the ASGSSR, vol. 2, №.8, Tb. (in Russian) (1941).

Kakhadze,I.R: Georgia in the Jurassic period. - Works of the Inst. Geol. ASGSSR, vol. III (VIII), Tb. (in Russian) (1948).

Kiknadze,T.Z: Geology, hydrogeology and limestone karst activity (case study of Abkhazia). Tb. (In Russian). (1979).

Kuchukhidze, G.T. et al.: Report on hydrogeological filming of the scale
1:50 000 of Zemo Imereti Plateau by the works of 1983-1986. Funds of „Gruzgeolupravlenija" (1986).

Kuznetsov, I.G.: Geological structure of the part of Western Georgia within Racha, Lechkhumi and Imereti. International Geological Congress, XVII session, USSR, excursion to the Caucasus, Georgian SSR, western part, L-M. (in Russian) (1937).

Lezhava, Z:: The Karst of Zemo Imereti Plateau and Its Surrounding Areas. Publishing House "Universali" Tbilisi, Georgia (in Georgian) (2015).

Lezhava, Z., K. Tsikarishvili, L. Asanidze, N. Bolashvili, N. Chikhradze and G. Chartolani: Ecological Investigation of karst water in the central part of Georgia. Lap Lambert Academic Publishing. Saarbrucken. ISBN: 978-620-2-02210-1 (2017).

Lezhava, Z., N. Bolashvili, K. Tsikarishvili, L. Asanidze and N. hikhradze: Hydrological and hydrogeological characteristics of the platform karst (Zemo Imereti Plateau, Georgia). 14th Multidisciplinary Conference on Sinkholes and the Engineering and Environmental Impacts of Karst. pp. 93-100. Rochester, USA(2015).

Lezhava, Z., K. Tsikarishvili, L. Asanidze, N. Chikhradze, G. Chartolani and A. Sherozia: Karst Relief Development History of Zemo Imereti Plateau. Georgia, Caucasus. J. Open J. Geol., 9, 201-212. https://doi.org/10.4236/ojg.2019.93014 (2019a).

Lezhava, Z., L. Asanidze, K. Tsikarishvili, G. Gaprindashvili and N. Chikhradze: About genesis of karst caldera of denudation-tectonic landform. Georgia, Caucasus. $19^{\text {th }}$ International Multidisciplinary Scientific Geoconference - SGEM 2019. Albena, Bulgaria. pp. 3$10(2019 b)$

Lezhava, Z., Z. Tintilozov and A. Jamrishvili: Technogenic factor and karst formation in Chiatura structural plateau. Summary Scientific Session of Vakhushti Bagrationi Institute of Geography, Tbilisi, pp. 21-22 (1991).

Lezhava, Z., Tintilozov Z.G. Gigineishvili: Results of survey of karst waters underground ways in Chiatura structural plateau. Summary Scientific Session of Vakhushti Bagrationi Institute of Geography, Tbilisi, p. 13-14 (1989).

Maksimovich, G.A.: Basics of Karst Science, Vol. 1, Perm (in Russian).

Maruashvili, L.: Basics of cave sciences (General Speleology). Tbilisi (1973).

Shiriashvili,O.I. and I.G. Vashakidze: Geological description of the sheets: K-38-52-VG; K-38-64-A, B (the Kvirila, Dzirula, Grone and Liakhvi river basins). Report of Liakhvi "GSP" by works of 19661970.Funds of the "Gruzgeolupravleniya", Tb. (in Russian) (1972.).

Sokolov, D.S.: The basic conditions for the development of karst. Gosgeoltekhizdat, Moscow (in Russian) (1962.).

Tintilozov, Z.K.: Karst caves of Georgia (Morphological analysis). Tb. (1976). 